\title{
Syllable phonology and cross-syllable temporal production in Greek
}

\author{
Elina Nirgianaki ${ }^{1,2}$, Athina Kontostavlaki ${ }^{1}$, Olga Nikolaenkova ${ }^{3}$, Maria \\ Papanagiotou $^{2}$ \\ ${ }^{1}$ Lab of Phonetics \& Computational Linguistics, University of Athens, Greece \\ ${ }^{1}$ Department of Primary Education, University of Athens, Greece \\ ${ }^{3}$ Department of General Linguistics, Saint Petersburg State University, Russia \\ https://doi.org/10.36505/ExLing-2017/08/0021/000323
}

\begin{abstract}
The present study examined the durations of voiced vs. voiceless fricatives as well as their intrasyllabic and intersyllabic duration effects as a function of variable focus applications. In accordance with a production experiment, the results indicate the following: (1) voiceless fricatives are significantly longer than voiced fricatives; (2) the voice distinction of fricatives has both intrasyllable and intersyllable duration effects as well as compensation duration effects; (3) focus application is confined on a lengthening effect of the vowel in stressed syllable context.
\end{abstract}

Key words: consonant, vowel duration, syllable, temporal production, Greek

\section{Introduction}

The main aim of the present study is an experimental investigation of segment durations as a function of intrasyllabic and intersyllabic segment variability in variable focus contexts. In particular, the duration of voiced vs. voiceless fricatives and sibilants are investigated as well as their duration effects at syllabic as well as intersyllabic level.

Other context and prosody factors being equal, a great deal of studies with reference to segmental temporality support the following hypotheses: (1) segmental sounds and especially vowels have different intrinsic durations and, thus, "low" vowels, such as /a/ are intrinsically longer than "high" vowels, such as /i/ or /u/ (e.g. Fourakis, Botinis, Katsaiti 1999); (2) voiceless fricatives are longer than voiced fricatives at all places of articulation (Nirgianaki 2014); (3) both low/high vowels and voiced/voiceless fricatives have compensatory effects at syllable domain. (4) open syllables are correlated with longer nucleus vowels than closed syllables (Maddieson 1985). Furthermore, a variety of prosodic factors, including lexical stress, focus and speech tempo, have respective duration effects on different segmental sounds (e.g. Fourakis et al. 1999).

However, the cross-syllable temporal effects of segment variability have hardly been investigated and we thus attempt to document the temporal behaviour of segmental sounds at both intra-syllabic and inter-syllabic levels and outline basic similarities and dissimilarities between them.

ExLing 2017: Proceedings of 8th Tutorial and Research Workshop on Experimental Linguistics, 19-22 June, Heraklion, Crete, Greece 


\section{Experimental methodology}

The speech material consists of the four key words ['masa] 'chew', ['maza] 'mass', ['mi $\theta \mathrm{i}]$ 'myths', ['miði] 'mussel' with lexical stress on the first syllable, produced at the context of the carrier phrase ['fonakse ðina'ta] 's/he said loudly'. Five female speakers at their early twenties, with standard Athenian Greek pronunciation, produced the speech material at a normal tempo in a sound-treated studio at Athens University Phonetics laboratory. The speech material was analysed with Praat programme and segment, syllable, word and utterance duration measurements were taken. The results were subjected to statistical processing with SPSS statistical package.

\section{Results}

Three-way ANOVAs (voicing $\mathrm{x}$ place of articulation $\mathrm{x}$ focus) were carried out for utterances, normalized words, syllable and segment durations as the dependent variables.

First, in terms of utterance durations and normalized word durations (word/utterance), significant differences were noted only in terms of focus [F $(1,112)=19.882, \mathrm{~F}(1,112)=74.169 ; \mathrm{p}<0.0001]$, indicating longer words and utterances in focus condition. Normalized syllable and segment durations were then counted, representing the ratio of each syllable and segment duration, respectively, to word duration. The results are presented in table I and figures 1-4.

Table I. Mean normalized duration for each segment and syllable and mean absolute duration for each word.

\begin{tabular}{|l|l|l|l|l|l|l|l|}
\hline Stimuli & C1 & V1 & S1 & C2 & V2 & S2 & Word (ms) \\
\hline 'masa & 0.250 & 0.317 & 0.567 & 0.264 & 0.169 & 0.433 & 353 \\
\hline 'maza & 0.265 & 0.369 & 0.633 & 0.159 & 0.208 & 0.367 & 381 \\
\hline 'miӨi & 0.277 & 0.299 & 0.575 & 0.186 & 0.173 & 0.425 & 363 \\
\hline miði & 0.295 & 0.304 & 0.600 & 0.252 & 0.214 & 0.400 & 372 \\
\hline \hline
\end{tabular}

At the syllabic level, the results indicated $[F(1,112)=10.327, F(1$, $112)=10.650 ; p<0.005]$ that first syllable (S1) was significantly longer while the second one (S2) significantly shorter when the fricative was /z/ in nonfocus condition. 

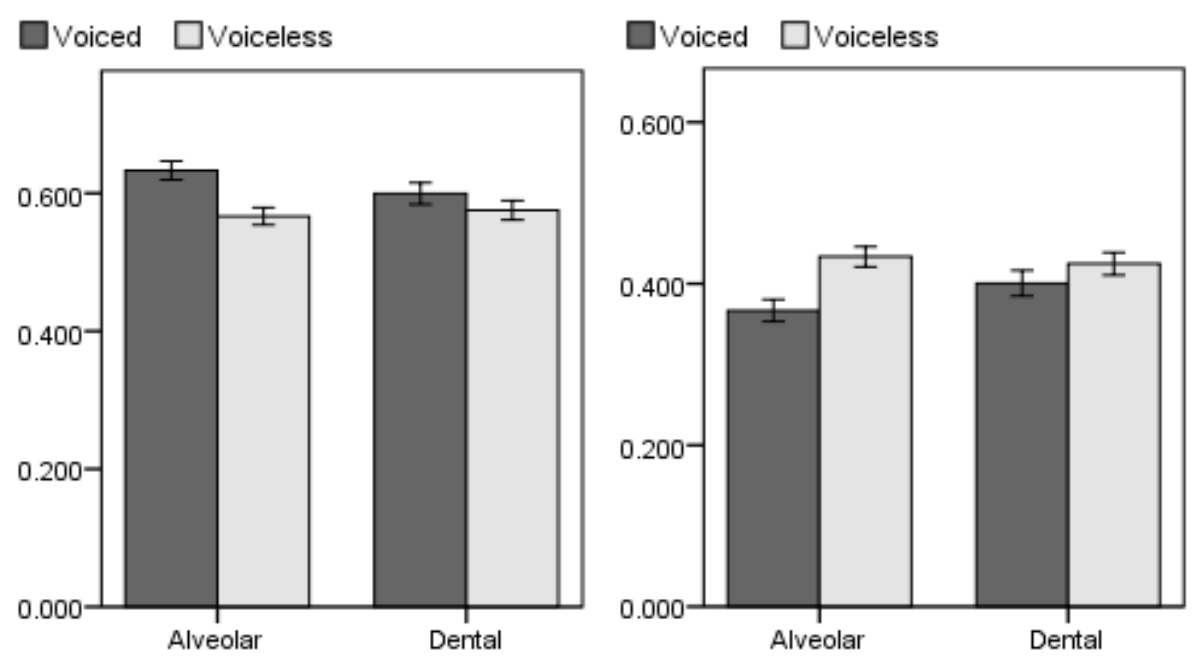

Figure 1. Mean normalized duration Figure 2. Mean normalized duration of first syllable as a function of of second syllable as a function of fricative voicing and place of fricative voicing and place of articulation. articulation.

At the segmental level, the first consonant (C1) was longer when the fricative was voiced and in non-focus condition $[\mathrm{F}(1,112)=8.888, \mathrm{p}<0.005]$, as well as when the fricative was dental $[\mathrm{F}(1,112)=41.975, \mathrm{p}<0.0001]$. The first vowel (V1) was significantly longer when fricative was $/ z /$ $[\mathrm{F}(1,112)=16.642, \quad \mathrm{p}<0.0001], \quad$ as well as in focus condition $[\mathrm{F}(1,112)=12.650, \mathrm{p}<0.005]$. Voiceless alveolar fricatives were significantly longer than voiced ones $[\mathrm{F}(1,112)=12.551, \mathrm{p}<0.005]$ in non-focus condition $[\mathrm{F}(1,112)=4.863, \mathrm{p}<0.05]$. A main effect for voicing $[\mathrm{F}(1,112)=51.435$, $\mathrm{p}<0.0001]$ revealed that second vowel (V2) was significantly longer when fricative was voiced.
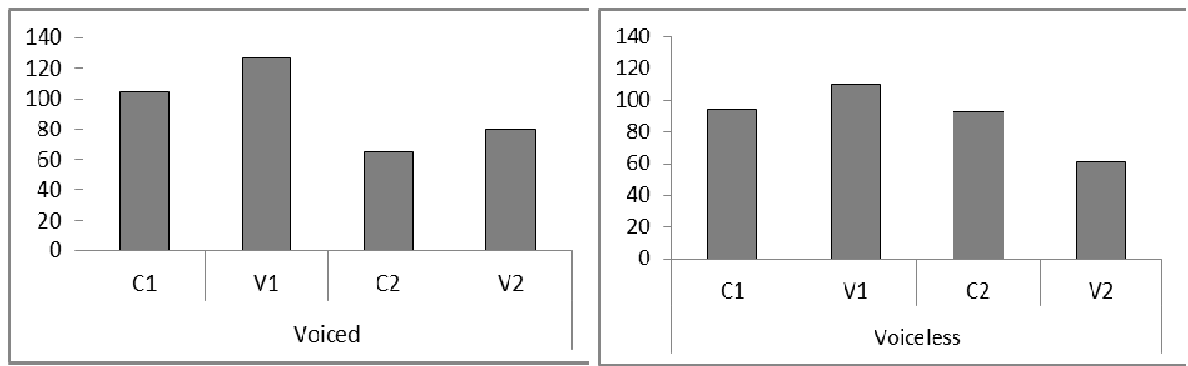

Figure 3. Mean normalized duration Figure 4. Mean normalized duration of segments as a function of fricative of segments as a function of fricative voicing. voicing. 


\section{Discussion and conclusions}

The results of the present study indicate the following. In non-focus context, there seems to be a strong effect of fricative's voicing at both syllabic and segmental level, which is even stronger in the case of alveolar fricatives/sibilants. Regarding fricatives themselves, voiced fricatives - and mainly alveolars - are shorter than voiceless ones. When words contain voiced fricatives, all other segments are longer, while at the same time the duration of the word and utterance are not affected. Hence, the present results reveal that voiced/voiceless fricatives exhibit compensatory effects not only at intrasyllable level, but also at intersyllable and word levels, affecting previous segmental and syllabic durations as well. On the other hand, the temporal effect of focus is confined on the lengthening of the stressed syllable's vowel.

Syllable structure temporal correlates have mostly been associated with the nucleus vowel, according to which open syllables are correlated with longer vowels and closed syllables with shorter vowels (Maddieson 1985). This hypothesis has been corroborated in several studies but it still remain a controvertial issue (see McCrary 2004 for relevant discussion). The open syllable lengthening effect suggested by Maddieson (1985) has partly been corroborated in Greek along with a compensatory shortening effect on the intrasyllable onset consonant (Chaida, Dimoula, Magoula, Nikolaenkova 2017). The results of the present study, however, indicate that a variety of compensatory duration effects take place at both intrasyllable and intersyllable levels, which is a reflexion of different syllable structures along with a variety of other prosodic contexts.

\section{Acknowledgements}

Our thanks to Maria Papanogiotou and Athina Tsiori for data recordings.

The Special Account for Research Grants, National and Kapodistrian University of Athens, has financed research and ExLing 2017 participation.

\section{References}

Chaida, A., Dimoula, I., Magoula, Nikolaenkova, O. 2017. Open vs. closed syllable phonology and temporal production in Greek (this volume).

Fourakis, M., Botinis, A., Katsaiti, M. 1999. Acoustic characteristics of Greek vowels. Phonetica 43, 172-188.

Maddieson, I. 1985. Phonetic cues to syllabification. In Fromkin, V. (ed.), Phonetic Linguistics, 203-221. London: Academic Press.

McCrary, K.M. 2004. Reassessing the role of the syllable in Italian phonology. Ph.D. thesis, UCLA.

Nirgianaki, E. 2014. Acoustic characteristics of Greek fricatives. Journal of the Acoustical Society of America, vol. 135, 2964-2976. 